\title{
Newton da Costa e a Filosofia da Quase-Verdade
}

\author{
DÉCIO KRAUSE \\ Universidade Federal de Santa Catarina
}

\begin{abstract}
This paper intends to introduce the three issues of Principia which will appear in a sequel honoring Newton da Costa's $80^{\text {th }}$ birthday. Instead of presenting the papers one by one, as it is common in presentations such as this one, we have left the papers speak by themselves, and instead we have preferred to present to the Brazilian readers, specialty to our students, some aspects of Newton da Costa's conception of science and of the scientific activity, grounded on the concept of quasi-truth, which he contributed to develop in a rigorous way. Da Costa is known as one of the founding fathers of paraconsistent logic, but his contributions go also to the foundations of physics, theoretical computation, model theory, algebraic logic, lattice theory, applications of non-classical logics to law and technology, etc. But perhaps his main contribution was to provide a basis for the birth of a school of logic in our country (Brazil), serving as teacher and inspiring new researchers for generations. It is a pleasure to have had so enthusiastic acceptation from the editors of Principia to organize these volumes. I would like to thank the contributors and the editors of Principia, specially Prof. Cezar Mortari for his help in organizing the issue.
\end{abstract}

Keywords: Newton da Costa, quasi-truth, scientific activity, science.

\begin{abstract}
Dedicado ao professor Newton da Costa, pelo exemplo.
A atividade científica é uma atividade conceitual na qual busca-se a quase-verdade de uma maneira racional.
\end{abstract}

N. C. A. da Costa

\section{Introdução}

Se olharmos para os títulos dos trabalhos publicados por Newton Carneiro Affonso da Costa, bem como para os assuntos neles desenvolvidos, podemos ser levados a conceber uma aparente desconexão, indo da lógica qua lógica, desenvolvendo ou sugerindo rumos para a criação de um sem número de sistemas lógicos, para chegar a aplicações da lógica à ciência do direito, à psicanálise, à física, ao problema da verdade, ao estabelecimento das bases para uma lógica indutiva, à tecnologia. Seus aportes teóricos alcançam a filosofia da ciência, a matemática, os fundamentos da física e a ciência da computação, sempre com a originalidade e profundidade que caracterizam os grandes pensadores. A impressão de certa descontinuidade, no entanto, é errônea. Sua obra, constituída ao longo de mais de 50 anos de atividade Principia 13(2): 105-28 (2009).

Published by NEL - Epistemology and Logic Research Group, Federal University of Santa Catarina (UFSC), Brazil. 
à qual se dedica integralmente, constitui-se de diversas facetas, alarga a fronteira da ciência em várias direções, aponta rumos férteis e precisos em várias frentes, mas tem sempre como pano de fundo uma preocupação eminentemente filosófica, visando articular uma concepção geral da atividade científica, procurando, como ele mesmo diz, entender a natureza e as limitações do ato de conhecer, "em especial, a essência do esforço da ciência" (da Costa 1990).

Newton da Costa é internacionalmente conhecido como um dos criadores da lógica paraconsistente, ${ }^{1}$ sendo para muitos o principal deles, em virtude de ter sido o primeiro a perceber (e a desenvolver) que sistemas não triviais envolvendo contradições poderiam ser elaborados com força suficiente para neles se fundar toda uma matemática, e não unicamente parte da aritmética, como resulta dos trabalhos de Nelson, por exemplo. Seus trabalhos nessa área também ultrapassam (e estendem) as lógicas (proposicionais) discursivas de Jaśkowski, lógicas essas que ele, juntamente com um discípulo de Jaśkowski, Dubikajtis, desenvolveu e divulgou. As lógicas paraconsistentes têm encontrado aplicações as mais variadas, desde questões teóricas em filosofia, envolvendo a discussão sobre os modos de se 'conviver' com situações inconsistentes, bem como alicerçando a noção de quase-verdade (ver abaixo), que o próprio da Costa desenvolveu, bem como ao conceito de complementaridade oriundo da filosofia de Niels Bohr, sem deixar de passar pela matemática e, notadamente nos últimos anos, principalmente à tecnologia. Da Costa ainda deu contribuições importantes aos fundamentos da física, da ciência da computação e a vários temas envolvendo as lógicas não clássicas e suas aplicações; para um apanhado geral dos sistemas de da Costa, ver da Costa, Krause e Bueno 2007.

Uma obra tão variada e ampla, na qual o autor não se contenta em traçar linhas gerais de argumentação, não pode ser entendida sem muito detalhe técnico, e seria impossível de ser resumida neste artigo. Por isso, procuraremos destacar, em linguagem mais informal possível (de certo modo contrariando a própria posição de da Costa) uma linha condutora do pensamento de nosso autor, a qual esperamos possa evidenciar aspectos de sua filosofia. Entender algo de sua forma de pensar a ciência nos parece fundamental para que possamos compreender a não explícita mas profunda argumentação filosófica que se esconde por detrás de textos invariavelmente técnicos.

Esperamos que este texto faça justiça a um dos maiores e mais originais pensadores brasileiros.

\section{Aspectos da ciência e da atividade científica: teoria da ciência}

Da Costa reconhece que a ciência envolve diversos aspectos, ou dimensões, como prefere chamar, tais como as seguintes: (i) aspectos históricos, psicológicos, sociais

Principia 13(2): 105-28 (2009). 
e éticos, (ii) aspectos epistemológicos, lógicos e metodológicos, e (iii) aspectos metafísicos. Suas justificativas para essa distinção são as seguintes. Os aspectos (i) surgem quanto se tem em conta que a construção da ciência se processa no decurso da história, não podendo ser bem entendida se não for estudada dentro de um contexto histórico. Se a ciência for estudada prescindindo-se desta dimensão, deve-se tornar claro que se está fazendo uma espécie e idealização. Com efeito, uma das lições fundamentais da história é a de que a ciência muda e se transforma completamente com o decorrer do tempo; a concepção de ciência de Aristóteles é evidentemente distinta da de Galileu, que por sua vez distingue-se profundamente daquela da dos partidários da teoria do caos. Sem a contraparte histórica, torna-se difícil negar, por exemplo, a categoria de ciência à astrologia, que até por volta de 1750 era considerada parte da matemática.

A ciência, por outro lado, é criação do cientista, estando sujeita a todas as vicissitudes e limitaçõe humanas. Na verdade, acentua da Costa, não se pode prescindir da dimensão psicológica da ciência, caso queiramos entendê-la em toda a sua complexidade. Deste modo, os problemas relacionados com os aspectos intuitivos do cientista perante o seu objeto de estudo, o que poderíamos denominar de intuitividade de uma determinada teoria científica, depende fundamentalmente de fatores de índole psicológica. Ademais, por ser uma atividade humana, a ciência é realizada dentro de um determinado contorno social, estando portanto sujeita a certas normas sociais e éticas, como bem ilustram as discussões sobre a engenharia genética. Outra questão dessa natureza á a seguinte: será que a matemática, por exemplo, acha-se condicionada a fatores sociais, como o econômico? Se assim for, aparentemente, o cientista hão poderá busca desinteressadamente a verdade, achando-se via de regra condicionado a fatores econômicos e pelos sociais em geral.

Os aspectos lógicos, epistemológicos e metodológicos da ciência constituem o que da Costa chama de teoria da ciência, e é sobre esses aspectos que ele dá atenção primordial em seus trabalhos. Como exemplo de problemas epistemológicos, podese citar a possibilidade e os limites do conhecimento científico, o conceito de verdade em ciência e o critério dessa verdade, se é que se pode dizer que há algum. Quanto aos aspectos lógicos, podemos apontar o estudo da estrutura das teorias científicas, os procedimentos de inferência em ciência, tanto dedutivas quanto indutivas, e a conveniência do uso do método axiomático. Dentre os aspectos metodológicos, estão os critérios para a verificação de hipóteses, a metodologia estatística e seu significado.

Quanto aos aspectos metafísicos, cabe lembrar que Popper, Kuhn e Lakatos foram alguns dos que evidenciaram que a ciência admite determinados pressupostos de natureza metafísica. De fato, acentua da Costa, a ciência acha-se intimamente relacionada com a metafísica no sentido de que o seu desenvolvimento se efetua em uma via balizada por princípios metafísicos. Por exemplo, mesmo nas ciências empí-

Principia 13(2): 105-28 (2009). 
ricas admite-se que o universo é em algum sentido regular, de sorte que pode ser por nós conhecido. Sem esta suposição, seria absurda qualquer tentativa de investigação científica. Da mesma forma, usualmente postula-se que há uma realidade a qual a física procura descrever adotando a preferência por outro princípio, a simplicidade das teorias alcançadas: uma teoria deve ser simples, uma explicação não deve supor mais do que o necessário, etc. $O$ físico também não abre mão de certos princípios de simetria, principalmente pelas vantagens matemáticas deles oriundas. Estas, dentre outras, são algumas das crenças metafísicas explícitas ou implícitas do físico, e os cientistas das demais áreas certamente as partilham ou assumem outras mais afeitas à sua atividade. Tais pressupostos, juntamente com fatores de índole pragmática, dos quais falaremos abaixo, delineiam os objetivos da ciência em cada uma de suas disciplinas.

Mesmo as ciências formais, como a lógica e a matemática, acham-se, segundo da Costa, condicionada a questões de índole metafísica. Por exemplo, a lógica clássica implica uma forma de atomismo. Com efeito, ainda que se possa fazer matemática e lógica de um ponto de vista puramente abstrato, o que constitui traço característico dessas disciplinas, quando se almeja aplicá-las ao real (vamos supor que a lógica seja a lógica clássica e que a matemática seja a tradicional, fundada sobre esta lógica), postulando que suas sentenças de certo modo descrevem ou dão conta de uma parcela da realidade, impõe-se à realidade um pressuposto metafísico forte, a saber, o de que uma proposição atômica, que essencialmente descreve um fato, é verdadeira ou falsa, independentemente com o que se passa com outras sentenças, isto é, de outros fatos, ou dos tipos de vínculos entre eles. Sob esta ótica, o mundo seria constituído por fatos atômicos, como já sustentaram Russell e Wittgenstein. Ainda que esta visão tenha limitações, como é sabido, fica patente que mesmo as ciências formais não estão livres de serem alcançadas por pressupostos metafísicos.

\section{Natureza, objetivo e classificação das ciências}

Para da Costa, a ciência busca a verdade de uma maneira racional. Seu objetivo é promover o conhecimento em certas áreas, conhecimento este que pode ser identificado, em uma primeira instância, com uma crença verdadeira e justificada, em conformidade com uma antiga caracterização. Naturalmente, tais definições são vagas, pois necessita-se esclarecer o que se entende por 'verdade', 'racionalidade, e 'justificação'. O esclarecimento desses termos, ou a tentativa de fazê-lo, é uma das interessantes ramificações da obra de da Costa, como veremos mais abaixo.

Outra faceta importante da teoria da ciência, na visão de da Costa, é a classificação das diversas disciplinas científicas, uma vez que é unicamente por meio dela que se pode ter uma visão esquemática geral da posição relativa das diversas discipli-

Principia 13(2): 105-28 (2009). 
nas. Houve muitas de tais classificações no decorrer da história, como as de Augusto Comte, de Spencer e de Carnap. Aqui, não trataremos de uma classificação detalhada, mas unicamente de apontar as principais classes ou categorias de ciências. Nesse sentido, da Costa admite haver três categorias principais de disciplinas científicas, a saber, as que compõem a ciência pura, as que formam a ciência aplicada e aquelas que são reunidas sob o rótulo de tecnologia. Em uma primeira aproximação, podemos dizer que a ciência pura busca a verdade pela verdade, independentemente das aplicações que a mesma possa ter e de sua utilidade. Assim sendo, a matemática, a física e a química enquadram-se no rol das disciplinas da ciência pura. A ciência aplicada, por seu turno, caracteriza-se pela dedicação a problemas precisos, que devem ser resolvidos para finalidades bem determinadas. Talvez a ciência pura e a ciência aplicada divirjam apenas na questão da ênfase que o cientista dá a sua atividade, sem que haja discrepâncias sobre a natureza da própria inquirição. Com efeito, não obstante em geral na matemática aplicada tratar-se de diversos temas pela relevância que têm, por exemplo para a física ou para a engenharia, os tópicos da matemática aplicada são puros, só que estudados e tratados tendo-se em mente alguma aplicação particular; tópicos como as séries de Fourier, a transformada de Laplace, a álgebra linear, por exemplo, pertencem igualmente à matemática pura e à matemática aplicada, e podem ser investigados per se ou visando alguma aplicação particular.

Quanto à tecnologia, ela consiste basicamente em um conjunto de técnicas sistematizadas com o intuito de se poder, como o seu auxílio, realizar determinadas tarefas, como a construção de navios, o aprimoramento de técnicas cirúrgicas, etc. O trabalho com computadores e a hidráulica, por exemplo, não passam de conhecimento aplicado, constando de técnicas geralmente fundadas na ciência pura, reunidas para que possam auxiliar médicos e engenheiros na consecução de determinadas tarefas. As ciências puras, por sua vez, dividem-se em duas classes, as formais (lógica e matemática) e as reais, ou empíricas. Estas últimas podem ser agrupadas em duas classes, as ciências naturais, como a física, a química e a biologia, e as ciências humanas, como a psicologia, a sociologia e a economia. A base da classificação precedente é óbvia, de forma que não precisamos nos ocupar aqui de sua justificação ou conveniência.

\section{Prescrição e descrição}

Na linha do pensamento de da Costa, podemos dizer que há basicamente duas abordagens possíveis para se fazer uma teoria da ciência, a prescritiva e a descritiva. $\mathrm{Na}$ primeira, quando se fala, v.g., dos métodos da física, procura-se enquadrá-la dentro das linhas metodológicas que se acha conveniente, mesmo que essas linhas não re-

Principia 13(2): 105-28 (2009). 
presentem a ciência 'real', 'viva'. Por outro lado, na abordagem descritiva, objetiva-se retratar a ciência tal como ela de fato é realizada, sem procurar impor-lhe normas que se ache convenientes. A distinção prescrição-descrição é ainda hoje muito enfatizada nas ciências humanas. Com efeito, há especialistas que sustentam ser a metodologia dessas disciplinas essencialmente a mesma da física ou, de forma mais geral, das ciências naturais. Não obstante, há metodólogos que defendem a tese de que a metodologia das ciências humanas deve ser completamente distinta daquela das disciplinas naturais, em especial da física. Os primeiros chamam-se monistas metodológicos, enquanto que os segundos são os dualistas metodológicos (às vezes, pluralistas). Por exemplo, há psicólogos que não admitem que os métodos usuais das ciências reais, como a mensuração, sejam utilizadas na psicologia, que segundo eles dependeria unicamente de métodos que lhe são peculiares, como a introspecção. Como é sabido, os behavioristas discordam completamente dessa posição.

Para entendermos a posição de da Costa a este respeito, não é necessário assumir uma posição absolutamente descritiva ou prescritiva. Com efeito, ele adota um meio termo: somente procuramos prescrever quando isso for absolutamente necessário. Aliás, segundo ele, sempre que fazemos filosofia da ciência projetamos na mesma alguns de nossos preconceitos e idéias já formadas, o que demonstra que uma tal filosofia não pode ter o caráter de objetividade da matemática ou da física. Todavia, da Costa sugere que adotemos uma posição mais objetiva e 'científica' possível, similar à do cientista independente, à qual ele por vezes se refere como 'filosofia científica'.

No restante desta exposição, salvo aviso explícito em contrário, trataremos unicamente das ciências naturais, em particular da física, a despeito de que as idéias que comentaremos se aplicarem em geral, com adaptações.

\section{O conhecimento científico}

Como já sugerido, ao se fazer ciência busca-se uma forma de conhecimento, o conhecimento científico. Mas, o que é o conhecimento científico, ou simplesmente 'conhecimento' como falaremos daqui para frente? Em uma primeira instância, podemos caracterizá-lo como constituído de crenças verdadeiras e justificadas, como sabidamente já colocou Platão. Apesar de todas as dificuldades que essa caracterização apresenta, como enormemente discutido na literatura filosófica (ver Chisholm 1966, cap.1), ela pode ser adotada em uma primeira aproximação. No entanto, como salienta da Costa, para tornar essa definição plausível, é preciso caracterizar devidamente os conceitos de verdade e de justificação (aqui, tomaremos o conceito de crença como suficientemente claro por si mesmo, de modo a simplificar a discussão). Uma outra delimitação posta por da Costa é entender o termo 'justificação'

Principia 13(2): 105-28 (2009). 
como significando justificação racional, com isso afastando outras formas de justificação, como revelações ou palpites. Por outro lado, o esclarecimento da noção posta de conhecimento científico necessitaria do auxílio de um case study de algumas situações em que o físico, por exemplo, expressou suas idéias a respeito do conhecimento em física e da forma como o cientista em geral enfrenta a questão do conhecimento. No entanto, não é possível tal digressão nessas notas; assim, admitiremos por simplicidade que a definição de conhecimento científico como crença racional verdadeira se impõe a si mesma como caracterizando de forma sensata o tipo de conhecimento que subjaz à atividade científica. Cumpre portanto esclarecer os conceitos de verdade e de racionalidade, bem como o de justificação. Mais à frente, voltararemos a este assunto.

\section{Racionalidade}

Quando uma atividade cognoscitiva pode ser considerada racional? Segundo da Costa, a racionalidade se caracteriza, ou se determina, por três notas principais: primeiramente, pauta-se pelo uso de uma determinada lógica. Ser racional, em determinada medida, é agir 'logicamente'. Da Costa, mais do que ninguém, está ciente da existência de uma enorme variedade de lógicas distintas da clássica. Assim, acentua que a atividade racional utiliza uma certa lógica dentro de um determinado contexto. Por exemplo, se a atividade racional se pauta pelos pressupostos da lógica clássica, não deve ser inconsistente, pois se o fosse seria trivial, já que de acordo com a lógica clássica de uma contradição pode-se derivar qualquer proposição. Além disso, caso inconsistente, a atividade racional não poderia ser verdadeira, pois de acordo com o princípio da contradição, dentre duas proposições contraditórias, uma delas deve ser falsa. No entanto, apesar de a lógica clássica alicerçar boa parte de nossa atividade racional ocidental, ela não precisa ser necessariamente a lógica a ser seguida na atividade racional. Da Costa, juntamente com O. Bueno e S. French, investigou aspectos do pensamento dos Azande, um povo da África central que segundo alguns aceitam raciocínios contraditórios. ${ }^{2} \mathrm{Da}$ Costa e colaboradores mostraram que, mesmo que esse seja o caso, não se pode creditar irracionalidade aos Azande, pois pode-se fundamentar suas formas básicas de inferência em uma lógica paraconsistente (da Costa, French e Bueno 1998). Isso mostra que a afirmativa de que em um determinado contexto a lógica subjacente deve ser única, nada implica que ela tenha que ser a lógica clássica.

A segunda nota da racionalidade é a crítica permanente. A atividade racional deve permanentemente submeter seus princípios, leis, axiomas, concepções, etc. à crítica. Parece, sem dúvida, que um dos traços marcantes da postura científica radica justamente na atitude crítica permanente, crítica esta que vai desde as fronteiras da

Principia 13(2): 105-28 (2009). 
experiência até os princípios mais abstratos. Ademais, esta crítica também faz com que as crenças científicas sejam superadas de modo normal por outras mais convenientes e mais aceitáveis. Por exemplo, é fato sobejamente conhecido que a mecânica newtoniana, uma das disciplinas de maior sucesso, precisou ser substituída, em determinados domínios, pela mecânica relativista, substituição essa que se originou após as sutis análises críticas de Albert Einstein referentes ao tempo e outras categorias do pensamento físico, mas isso não implica que a mecânica newtoniana foi provada ser falsa, como comumente se acredita. Este ponto será abordado mais abaixo. Aliás, uma das teses principais de da Costa em seu livro de 1980, que pode ser extrapolada da lógica para a ciência em geral, é a de que em ciência não pode haver dogmas, verdades eternas ou princípios (mesmo lógicos) que devam permanecer válidos em todos os domínios do conhecimento. Para ele, todo e qualquer conceito pode ser dialetizado (expressão que ele empresta de Gaston Bachelard e Ferdinand Gonseth, mas lhe dá conotação própria), ou seja, modificado, ampliado ou mesmo posto entre parênteses pela crítica permanente.

A terceira característica fundamental da racionalidade diz respeito à sua contraparte indutiva. O pensamento racional, em particular o pensamento científico, não é regido unicamente por meio de normas dedutivas mas, sobretudo, por regras indutivas. Essas regras são estudadas pelas lógicas indutivas, constituindo-se em regras que permitem que se realizem inferências nas quais a conclusão não se segue com necessidade absoluta das premissas, mesmo que essas sejam verdadeiras. $\mathrm{O}$ mecanismo indutivo assegura apenas certa plausibilidade, que pode ser aferida por meio de probabilidades subjetivas e, de modo geral, a lógica indutiva encontra-se intimamente relacionada com tais probabilidades, sejam elas qualitativas, sejam quantitativas. Com efeito, existem vários tipos de inferência indutiva, como a indução simples, a inferência estatística e o método hipotético-dedutivo (todas essas formas são analisadas em da Costa \& French 2003). Convém ressaltar que da Costa não utiliza a palavra 'indução' em sentido estrito, como fazem certos pensadores indutivistas e mesmo Popper, mas emprega-a no sentido mais amplo possível, designando qualquer inferência não dedutiva, incluindo o método hipotético-dedutivo, por meio do qual elaboramos nossas teorias e hipóteses. Assim, a terceira característica fundamental da atividade racional centra-se no uso sistemático da inferência indutiva, de modo que podemos dizer que sempre inferimos e aceitamos certas proposições ou teorias de modo a otimizar nossos graus de crença.

Podemos agora retornar ao tema do conhecimento, como prometido acima. Convém sublinhar que a palavra conhecimento, como a utilizaremos, não se coaduna exatamente com o seu uso em sentido tradicional. Com efeito, neste sentido, conhecimento é uma crença que deve ser verdadeira e justificada. Mas, se o conhecimento é tomado como verdadeiro e se sabemos disso mediante um critério razoável como, por exemplo, a evidência, não haveria sentido pretender revisá-lo ou abando- 
nar certo conhecimento adquirido. Em contraste, o uso que da Costa faz do termo 'conhecimento científico' é tal que dá a entender que um conhecimento pode ser modificado, revisado ou abandonado em detrimento de outro, que se adapte melhor a certas suposições que o cientista desenvolve. De acordo com essa perspectiva, a ciência busca, segundo da Costa, um tipo de conhecimento que não se enquadra totalmente na definição clássica, muito embora possa-se admitir que, em certas circunstâncias, é possível identificar o conhecimento científico com o conhecimento segundo a definição tradicional, por exemplo, quando tratamos de certos enunciados simples da experiência, como o 'conhecimento' que tenho que minha caneta encontra-se na minha mesa no momento em que digito este texto.

\section{Verdade e quase-verdade}

Para a compreensão do conceito de racionalidade, é necessário que se especifique o que se entende por verdade, principalmente porque, como se sabe, há várias concepções do conceito de verdade, sendo que três delas nos parecem importantes para a atividade científica, a saber, a teoria da correspondência, a teoria pragmática e a teoria da verdade como coerência. Segundo a teoria da correspondência, na sua forma, digamos, mais atual, a verdade é um atributo de sentenças ou proposições. Uma proposição é verdadeira se ela 'corresponde à realidade', ou seja, se o que ela asserta é de fato o que é, reflete o real. Este ponto de vista também pode ser descrito dizendo-se que a verdade é a coincidência entre pensamento e realidade.

Claro que as conceituações anteriores, que sofreram transformações nas mãos de notáveis filósofos, ${ }^{3}$ mas permaneceram demasiadamente vagas para servir de fundamento para uma sistematização da teoria da ciência. Coube a Alfred Tarski, por volta de 1936, dar uma versão considerada aceitável da teoria da correspondência, que no entanto não deixa de apresentar outros senões, como comentaremos abaixo. 0 trabalho de Tarski, no entanto, mostra que é possível dar uma versão rigorosa da teoria da correspondência que elimina os paradoxos comuns relacionados a esta noção, como o paradoxo do mentiroso. Além do mais, permite demonstrar teoremas de grande significação sobre o referido conceito. Normalmente, pensa-se que a verdade que se busca nas ciências empíricas é a verdade como correspondência. Assim, as teorias físicas, por exemplo, comportariam sentenças verdadeiras na medida em que refletissem a realidade do mundo físico; elétrons, prótons, energia, membranas, etc., representariam objetos reais ligados por meio de relações cuja descrição seria o objeto da ciência. É bem provável, lembra constantemente da Costa, que boa parte dos físicos ainda pense deste modo.

Dito isto, podemos nos referir a um dos principais aspectos da concepção de ciência de da Costa, a saber, o de que, na realidade, a atividade científica de suplan-

Principia 13(2): 105-28 (2009). 
tação de teorias não consiste na sua refutação, como queria Popper, mas no confinamento de teorias a particulares domínios de aplicação. Segundo ele, uma teoria, que inicialmente poderíamos imaginar se aplicando amplamente (como a mecânica de Newton foi suposta ser por cerca de dois séculos) acha-se suplantada quando se reconhece que ela já não se aplica mais amplamente, havendo outra que cumpre melhor esta tarefa (como, no caso, a mecânica relativística geral de Einstein em certos domínios), mas entende-se que se domínio acha-se restringido a certos limites. Com efeito, a mecânica newtoniana não pode ser empregada na descrição de certos fenômenos, devendo ser substituída pela relatividade geral ou pela mecânica quântica. No entanto, a mecânica de Newton continua sendo utilizada em situações as mais variadas, tais como na descrição dos movimentos planetários, no estudo de satélites artificiais (a velocidades reduzidas comparadas à velocidade da luz), em engenharia, etc. O problema que se origina pode então ser colocado da forma seguinte: se a mecânica newtoniana não é verdadeira no sentido da teoria da correspondência, como é ainda largamente utilizada, e qual a razão de seu emprego?

Tais considerações sugerem que talvez a verdade que o físico persegue, mesmo que inconscientemente, seja um conceito distinto do correspondencial. Com Irene Mikenberg e Rolando Chuaqui, da Costa desenvolveu o conceito de quase-verdade, que parece mais afeito às ciências empíricas (Mikenberg et al. 1986). Posteriormente, com Steven French e Otávio Bueno, da Costa estendeu e aplicou este conceito à filosofia da ciência (da Costa \& French 2003; da Costa \& Bueno 2007, onde há referências para outros trabalhos desses autores). A quase-verdade, inicialmente denominada de verdade pragmática, tem motivação nos trabalhos dos filósofos pragmatistas norte-americanos, Peirce, James e Dewey, principalmente Peirce, mas não pretende representar ou esquematizar qualquer de suas idéias (daí a mudança de denominação, que visa evitar qualquer comprometimento com exegese desses filósofos). Em síntese, dizer que uma proposição $P$ é quase-verdadeira em um domínio $D$ significa dizer que as coisas se passam em $D$ como se $P$ fosse verdadeira em $D$ no sentido da teoria da correspondência. Em outras palavras, $P$ 'salva as aparências' em $D$. Mencionaremos dois exemplos. O sistema de Ptolomeu é quase-verdadeiro quando nos limitamos a observações dos astros que nos cercam com aparelhos rudimentares, como pequenas lunetas. Ou seja, 'tudo se passa' como se estivéssemos parados e os astros estivessem circulando ao nosso redor. Dentro de limites, a teoria de Ptolomeu é verdadeira estrito senso, ou seja, ele é quase-verdadeira. Um segundo exemplo vem do átomo de Bohr, que pode ser usado para o estudo de certos tipos de radiações do átomo de hidrogênio. Dentro de limites, tudo se passa como se a teoria de Bohr fosse verdadeira em sentido correspondencial. O problema é dar sentido preciso a essas idéias, e é aí que o estilo da Costa de filosofar se faz presente.

Com efeito, a teoria da quase-verdade foi matematizada, ao estilo tarskiano, no mencionado trabalho com Mikenberg e Chuaqui (Mikenberg et al. 1986). Esses

Principia 13(2): 105-28 (2009). 
autores fizeram com a quase-verdade o que Tarski fez com a teoria da correspondência. Mais ainda, mostraram que a teoria de Tarski reduz-se à quase-verdade quando as proposições são quase-verdadeiras, salvando as aparências, pelo simples fato de serem verdadeiras em sentido correspondencial. Em geral, para se poder afirmar que uma proposição $P$ é quase-verdadeira em $D$, torna-se preciso comparar suas consequências lógicas com proposições que são verdadeiras segundo a teoria de Tarski, que são denominadas de proposições básicas. Essas englobam, por exemplo, as proposições que se considera expressam experiências simples ou sentenças já firmemente estabelecidas em sentido tarskiano. Por exemplo, na física usualmente se recorre a constructos teóricos como cordas (na teoria das cordas), energias potenciais, etc., que dificilmente se poderia pensar como 'existindo' estritamente na realidade. Parece que se tratam de meros artifícios dos quais lançamos mão para dominar, de modo quase-verdadeiro, o nosso contorno, unicamente para salvar as aparências, para dar conta da experiência.

Mais tecnicamente, uma sentença ou proposição $P$ de uma linguagem conveniente $L$ é quase-verdadeira em uma estrutura $A$ (que tem domínio $D$ ) se essa estrutura pode ser estendida a uma estrutura (chamada de $A$-normal) $B$ tal que $P$ seja verdadeira no sentido tarskiano em $B$. Há condições necessárias e suficientes para que a estrutura $A$ possa ser estendida a uma estrutura $B$, mas ela não nos importam aqui (ver Mikenberg et al. 1986). Em $A$, algumas das relações são parciais, ou seja (consideremos apenas o caso de relações binárias), não se aplicam a todos os pares de objetos do domínio. Para alguns pares, permanece indeterminado se eles satisfazem ou não a relação, contrariamente às relações conjuntistas usuais, para os quais os pares satisfazem ou não satisfazem a relação (as relações usuais são sempre totais). A questão então da extensão de $A$ a $B$ está em se saber se as relações parciais podem ser tornadas totais, e então o conceito de verdade de Tarski se aplica a elas. Deste modo, se $A$ pode ser estendida a uma $B$ na qual $P$ seja verdadeira em sentido usual (tarskiano), pode-se dizer que $P$ 'salva as aparências' em $A$ ou seja, tudo se passa em $A$ como se $P$ fosse verdadeira em sentido correspondencial. A idéia é realmente interessante, e se adapta muito bem ao que aparentemente se espera de um conceito de verdade nas ciências empíricas. Com efeito, parece que podemos esperar que haja relações totais unicamente nos domínios usuais da matemática, mas que nos campos de estudo das ciências empíricas, esse conceito tenha que ser amenizado.

De fato, a história da ciência mostra que teorias, mesmo as muito bem fundamentadas e aceitas como literalmente refletindo a realidade, eram falsas. Portanto, nada impede que as teorias atuais e futuras, por mais plausiveis e sensatas que possam parecer, mostrem-se também ser falsas em sentido correspondencial. Este seria um dos motivos pelos quais o cientista parece necessitar de um conceito de verdade mais ameno que o correspondencial, e a quase-verdade aparentemente responde satisfatoriamente a esta demanda (porém, ver o final destra seção). Uma boa razão 
para defender a quase-verdade reside no fato de que ela não exclui a teoria correspondencial; na verdade, pode ocorrer que a quase-verdade tenda, como o decorrer do tempo, como aliás desejava Peirce, para a verdade estrito senso, ou seja, que as proposições quase-verdadeiras tornem-se verdadeiras em sentido correspondentista. Assim, a ciência empírica procuraria modelar a realidade por meio de sistemas conceituais que permitem prever (e retrover) em certos domínios, salvando as aparências em sentido da quase-verdade. Deste modo, podemos dizer que, para da Costa, a ciência é uma atividade racional cujo objetivo é a busca da quase-verdade e, quando possível, da verdade como correspondência (ver da Costa \& French 2003 para uma exposição detalhada da teoria, ou o capítulo 3 de da Costa 1999 para uma exposição mais informal). ${ }^{4}$

Interessante observar que o conceito de quase-verdade, como o conceito de Tarski, depende da metamatemática empregada, em geral uma teoria de conjuntos (que podemos assumir, sem perda de generalidade, como sendo ZFC - ZermeloFraenkel com o axioma da escolha). Assim, como acontece com o conceito semântico de Tarski, uma possível alteração dessa metamatemática, por exemplo assumindo que se trata de uma teoria incompatível com ZFC, pode alterar a (quase-)veracidade de uma sentença. Este ponto, obviamente relevante filosoficamente, merece atenção.

\section{Justificação}

Pelo que vimos acima, podemos dizer que, em uma primeira instância, um conhecimento se justifica pelo fato de ser racional. Um conhecimento é uma crença quaseverdadeira, racionalmente instituída e defendida (justificada). O objetivo básico do cientista, deste modo, consistiria em traçar sistemas conceituais sobre porções da realidade pelo emprego sistemático de teorias que são quase-verdadeiras relativamente aos domínios em questão. Dada uma teoria $T$, que é formulada para dar conta de um certo domínio $D$ do conhecimento, para que $T$ seja quase-verdadeira em $D$ é preciso que ela 'salve as aparências' em $D$, ou seja, constitua processo de cálculo ou modelo a partir do qual seja possível fazer previsões que estejam de acordo com os enunciados básicos de $D$, que assume-se são verdadeiros estrito senso. $\mathrm{O}$ conjunto dos enunciados básicos de $D$ constituem o que da Costa chama de arcabouço empírico de $D$. Em geral, este arcabouço empírico não contém unicamente enunciados empíricos, como os enunciados protocolares dos positivistas lógicos, mas também princípios amplos que são pressupostos e que são oriundos das diversas ciências, como princípios mecânicos e mesmo outros de caráter metafísico, tais como certas situações referentes à simplicidade e simetria em física. Uma teoria quase-verdadeira em um certo domínio $D$, módulo um arcabouço empírico, será então sempre válida 
neste domínio. Caso haja discrepâncias, deve-se restringir $D$ quanto à sua amplitude e ao arcabouço a ele subjacente. Daí podermos concluir que o câmbio de teorias se verifica pela restrição do domínio de aplicação das mesmas, e não propriamente mostrando-se que as teorias precedentes são falsas. Um lema da concepção de da Costa poderia ser posto da forma seguinte: uma teoria quase-verdadeira em um certo domínio será sempre quase-verdadeira neste domínio.

Todavia, parece fato inegável o de que há superação de teorias. Na linha do pensamento exposta acima, a explicação para isto é a seguinte: o fato de uma teoria ser quase-verdadeira não é a única qualidade de uma teoria que se impõe ao pesquisador. Normalmente, pode haver várias teorias quase-verdadeiras que dão conta dos mesmos fenômenos em um determinado domínio $\mathrm{D}$ e a escolha entre elas se faz tendo em vista critérios pragmáticos, tais como a simplicidade matemática, a intuitividade do modelo formulado e a amplidão de seu campo de aplicação. Além disso, para se dar conta da escolha e da aceitabilidade de teorias, deve-se recorrer ao grau de crença das mesmas, que segundo da Costa pode ser entendido como dado por um tipo de probabilidade subjetiva que ele desenvolveu e denominou de probabilidade pragmática (da Costa 1986). O cálculo de probabilidades resultante aplica-se não somente a enunciados simples que são verdadeiros ou falsos no sentido da teoria da correspondência, mas também a enunciados complexos, como hipóteses e mesmo a teorias, que podem ou não serem quase-verdadeiras. O grau de crença não se aplica à verdade estrita de tais enunciados, mas à sua quase-verdade, e isso faz com que uma teoria como a mecânica newtoniana possa ter probabilidade pragmática $1 \mathrm{em}$ certos domínios, mesmo que se saiba que ela não é estritamente verdadeira nesses domínios.' Deste modo, supera-se a grande dificuldade que envolvia a atribuição de probabilidades a teorias complexas, como muitas das teorias da física. Da mesma forma, superam-se certas idéias de Popper, para quem, num universo infinito, a probabilidade de qualquer lei universal é necessariamente igual a zero (Popper 2002, Ap. VIII).

Com o recurso da teoria da probabilidade pragmática, da Costa pode conceber razoavelmente (novamente contrariamente a Popper) a existência de uma lógica indutiva (na verdade, é possível conceber uma enorme variedade de tais lógicas). Entende ele que uma indução é qualquer raciocínio não dedutivo mas que é plausível, sendo essa plausibilidade mensurada pela probabilidade pragmática da conclusão, dadas as premissas como verdadeiras. Suas idéias a este respeito acham-se em da Costa 1986 e, de forma expositiva, em da Costa 1981. A lógica indutiva, deste modo, justifica-se como essencial para fixar nosso grau de crença em uma proposição (ou em uma teoria), bem como para podermos ponderar acerca de nosso sistema de crenças científicas. Isso, no entanto, não quer dizer que o grau de crença deva ser sempre um valor numérico ou quantitativo. Pelo contrário, na maioria dos casos, é meramente qualitativo. Assim, a posição de da Costa permite solucionar o problema

Principia 13(2): 105-28 (2009). 
da inducão em sentido amplo. Segundo ele, seguimos inferências indutivas como, por exemplo, empregando o método hipotético-dedutivo na construção de teorias, sempre maximizando nossos graus de crença. É, no entanto, evidente que não podemos provar que por este caminho chegaremos necessariamente à verdade como correspondência, nem mesmo à quase-verdade. A única coisa que podemos sustentar é que seguimos nossas evidências da melhor maneira possível e, por conseguinte, a indução se mostra racional no sentido de que procedemos otimizando nossos graus de crença, medidos pela probabilidade pragmática, embora isso constitua algo subjetivo que não nos garante qualquer verdade absoluta acerca de nossas concepções. A indução, não obstante, é um processo racional e nisso radica a sua única justificação possível.

De acordo com esta concepção, podemos então dizer que a ciência busca teorias quase-verdadeiras. No decurso do tempo, vamos elaborando teorias cujos domínios são cada vez mais amplos, mediante processo cada vez mais rigorosos e precisos. Assim sendo, a ciência talvez atinja a verdade absoluta no sentido da teoria da correspondência, não obstante este fato jamais poder ser provado (como salientado por Popper). Segundo da Costa, nesta objetividade da ciência pode ser demonstrada ser conseqüência da própria índole do processo científico recorrendo-se, por exemplo, ao teorema de de Finetti. ${ }^{5}$

\section{Teorias científicas}

Basicamente, uma teoria científica $T$ é constituída pelos seguintes itens: (i) uma estrutura matemática, (ii) um domínio de aplicação (que pode representar vários domínios reunidos em um só), e (iii) um conjunto de regras de conexão.

O domínio $D$ de uma teoria é a porção do universo ao qual ela se aplica. Por exemplo, a mecânica newtoniana acha-se hoje correlacionada com fenômenos de baixa velocidade comparada à velocidade da luz e massas não muito discrepantes daquelas com as quais convivemos no dia a dia, ao passo que a mecânica relativística geral tem por domínio o universo macroscópico como um todo. ${ }^{6} \mathrm{~A}$ teoria do átomo de Bohr, por outro lado, pode ser usada unicamente para a previsão de certas formas de radiação de átomos de elementos simples, como o hidrogênio ou o helio. Para da Costa, não há teoria sem que se explicite o seu domínio de aplicabilidade pretendido, o que inclui também a precisão e a exatidão dos métodos para se checar e comprovar as suas predições, geralmente encapsulados em uma 'teoria da mensuração', como aquela apresentada por Suppes e Luce (Suppes \& Lucce 1987). Se $T$ for uma teoria potente e boa, em geral ela se aplica a vários domínios distintos, de modo que, sugere ele, a fim de que sejamos precisos, em vez de falar de um só domínio, deveríamos nos referir a uma coleção deles.

Principia 13(2): 105-28 (2009). 
A estrutura matemática de $T$ não passa de uma estrutura no sentido que se estuda abstratamente em matemática. Mais precisamente, trata-se de uma estrutura conjuntista no sentido de Bourbaki (Bourbaki 1968, cap.4). Por exemplo, na mecânica quântica não relativista, a estrutura usualmente utilizada é a de um espaço de Hilbert, ainda que haja outras abordagens. Uma vez que o estudo de tais estruturas se faz dentro da matemática, fica patente a importância desta para a ciência como um todo. Isso traz ainda uma questão interessante e pouco explorada (mas veja-se Krause \& Bueno 2008); tendo-se em vista a existência de diferentes matemáticas (e.g., a matemática, ou 'modelo' de Solovay), ${ }^{7}$ constitui sem dúvida tarefa essencial do filósofo da ciência investigar as estruturas subjacentes às diversas teorias científicas sob a perspectiva dessas diferentes teorias. Uma mudança de arcabouço matemático pode trazer conseqüências filosóficas importantes.

Quanto às regras de conexão, elas não são regras estrito senso, como as regras de inferência dos sistemas lógicos. Elas podem ser vistas mais como artifícios verbais e metodológicos que permitem correlacionar uma teoria com seu domínio de aplicabilidade. Segundo da Costa, esta parte da ciência enquadra-se essencialmente na metodologia, que fornece os procedimentos e técnicas explícitos e implícitos pelos quais testamos, corroboramos e verificamos nossas teorias. Normalmente, tais regras e métodos, ou seja, os artifícios de correção, envolvem concepções estatísticas, teorias da mensuração e organização de dados. Cada ciência empírica, como a física, a química ou a biologia, possui seus processos padrão para efetuar a ligação entre teoria e realidade, entre teoria e a experiência. Fundamentalmente, a teoria das regras de conexão encerra três categorias de questões relacionadas a temas metodológicos: (a) a estatística, (b) a teoria da mensuração (ou medição), e (c) as técnicas de observação e de verificação (teoria da instrumentação). Por outro lado, um dos problemas centrais da teoria da ciência é o da axiomatização das diversas teorias científicas. Axiomatizar uma teoria consiste em se exibir a sua estrutura matemática subjacente, de acordo com a posição de Suppes (Suppes 2002), o que é alcançado, desde que se trabalhe em uma teoria de conjuntos, por um predicado conjuntista (uma fórmula da linguagem da teoria de conjuntos que expressa os pressupostos matemáticos da teoria). Com Rolando Chuaqui, da Costa deu um sentido preciso a este conceito; esses autores definiram o que se denomina de predicado de Suppes (da Costa \& Chuaqui 1988) e, usando esta técnica, juntamente com Francisco Doria, axiomatizou teorias como a relatividade geral, a mecânica de Hamilton, a mecânica de Dirac, dentre outras. Com o autor deste artigo, investigou vários sistemas de lógica nos quais o conceito de identidade é enfraquecido, visando tratar de alguns pressupostos (por exemplo, de Schrödinger) sobre a identidade de objetos quânticos (da Costa \& Krause 1994, 1997) e também de teorias que possam encerrar um conceito de complementaridade (da Costa \& Krause 2006).

Isso posto, podemos compreender a noção de paradigma na concepção de da

Principia 13(2): 105-28 (2009). 
Costa. Numa determinada ciência, quando se aceitam certas pressuposições e teorias como sendo quase-verdadeiras em preferência a outras rivais, tem-se um paradigma. Enquanto um paradigma vige, como muito bem notou Kuhn, em geral não se discute a quase-verdade ou mesmo a verdade das teorias em voga. A atividade dos cientistas, em sua maior parte, consiste em resolver problemas 'interiores' a elas. Dentro desta perspectiva, em vez de falarmos de uma teoria ou de um pequeno número de teorias, deve-se falar de sistemas amplos de teorias, que são as teorias que estão em voga e, deste modo, torna-se fácil falar em mudança de paradigma e de comensurabilidade de teorias, dois tópicos de grande relevância em filosofia da ciência, como se sabe. Além de tudo, esta atitude faz com que não seja descabida, do ponto de vista lógico, a atividade científica que trabalha concomitantemente com sistemas incompatíveis entre si. Com efeito, dentro do esquema de sistemas de teorias, pode-se inclusive adotar uma perspectiva racional para sistemas que envolvam teorias incompatíveis. A teoria do átomo de Bohr, por exemplo, assenta-se na eletrodinâmica tradicional, mas incorpora aspectos quânticos que são incompatíveis com aquela. Na física presente, reconhece-se que o chamado modelo padrão da física de partículas é formado por duas teorias que ainda não se sabe como compatibilizar formalmente de modo adequado, a teoria das interações eletrofracas e a das interações fortes. Os físicos trabalham como se houvessem duas teorias paralelas, ambas quase-verdadeiras em seus particulares domínios de aplicação. Para uma adequada unificação, reconhece-se que a gravidade precisa ser incorporada, mas ainda não se sabe ao certo como proceder. Por ora, o modelo padrão funciona como um sistema de teorias as quais não se sabe ao certo como tratar (logicamente) em conjunto. Isso, no entanto, não assusta o filósofo, pois um tal sistema de teorias pode ser alicerçado sobre uma lógica paraconsistente, em especial uma lógica paraclássica. ${ }^{8}$ Sem que uma tal proposta pretenda 'solucionar' o problema do físico, a alternativa mostra que o sistema como um todo se adéqua aos critérios de racionalidade postos acima.

As observações acima servem para corroborar o fato de que a teoria da ciência evolui com a própria ciência. Com efeito, ninguém pensaria hoje em descrever a física atual recorrendo-se a esquemas conceituais do século XIX. Na verdade, existe um interplay entre ciência e teoria da ciência. Exagerando um pouco, pode-se ser tentado a dizer que a teoria da ciência é impossivel porque, para elaborá-la, necessitamos saber o que é a ciência e, para saber o que é a ciência, necessitamos da teoria da ciência, que nos diz quais são os métodos de verificação, de experimentação, as regras aceitáveis, etc.

\section{Metodologia}

A metodologia trata dos métodos utilizados nas diversas ciências; aqui, ficaremos restritos às ciências empíricas. Naturalmente, não há sentido adentrarmos a ques-

Principia 13(2): 105-28 (2009). 
tões clássicas a respeito da metodologia, mas convém abordarmos alguns aspectos metodológicos da ciência, situando-nos relativamente a este tópico selecionando alguns conceitos para que possamos descrever com mais detalhe a posição filosófica de da Costa.

Iniciemos com as noções de causa e efeito e, em geral, o determinismo, que perderam muita de sua importância depois do advento da física quântica usual, especialmente tendo-se em mente a interpretação probabilística da mesma, devida a Max Born. ${ }^{9}$ Porém, não há dúvida de que causa é uma noção indispensável em muitas situações. Na medicina, por exemplo, na técnica do diagnóstico médico, não se pode prescindir das noções de causa e efeito, e o mesmo sucede com várias outras circunstâncias, como freqüentemente ocorre na economia, na sociologia e na biologia. Porém, se supusermos que não há uma perfeita correspondência entre os mecanismos de causa e efeito da forma como os concebemos usualmente, e os processos naturais, como parece evidenciar a física atual, como pode ser possível que se estudem ainda hoje noções aparentemente antiquadas como causa, efeito e determinismo? Se nos colocarmos do ponto de vista da quase-verdade, aparece uma resposta interessante: é quase-verdadeiro que, dentro de certas circunstâncias, as noções de causa e efeito funcionam do modo corriqueiro, tudo se passando como se houvessem causas e efeitos reais. Claro que com isso não pretendemos negar a possibilidade de tal existência. Portanto, como salienta da Costa, na metodologia atual, pode-se e deve-se estudar noções como causa e efeito, bem como os métodos de Mill e toda a teoria geral das condições necessárias, condições suficientes, condições necessárias e suficientes, etc., como tratadas por von Wright em (von Wright 1951). Deste prisma, é preciso cautela quando se fala em 'noções antiquadas', 'conceitos ultrapassados', pois seu estudo pode se afigurar relevante desde que justificado do ponto de vista da quase-verdade.

Questões referentes à classificação, definição e inferência, por exemplo, também podem ser estudadas com proveito tendo-se em mente esta postura. $O$ método hipotético-dedutivo, por exemplo, enquadra-se perfeitamente no esquema de uma lógica indutiva baseada no conceito de quase-verdade, podendo-se mostrar, como em da Costa 1989, que em certo sentido qualquer processo indutivo pode ser reduzido a uma forma do método hipotético-dedutivo, que da Costa chama de 'método hipotético-dedutivo generalizado' (ver também da Costa \& French 2003).

\section{A indução e o valor pragmático da ciência}

Para da Costa, a ciência é uma atividade racional na qual se busca a quase-verdade em determinadas regiões de nosso contorno. A atividade científica consiste em se tentar captar o real, ou de formular esquematicamente nossas concepções acerca do

Principia 13(2): 105-28 (2009). 
real através de esquemas e modelos conceituais, geralmente calcados na matemática, de modo a se poder explicar e prever. Assim, a atividade científica (logo, a ciência) é eminentemente indutiva: a 'realidade' é dominada através de tentativas e erros, utilizando-se métodos como a analogia, a formulação de hipóteses e a estatística. Os esquemas conceituais e modelos assim obtidos enquadram-se sempre na categoria das estruturas matemáticas, qualitativas ou quantitativas. Efetivamente, não pode haver ciência sem matemática. Este, segundo da Costa, seria o denominador comum de todas as ciências reais.

Conceituando-se ciência (real) deste modo, fica patente que a diferenciação entre ciência e não-ciência torna-se vaga como, aliás, não poderia deixar de ser. Com efeito, como já insistido antes, a separação entre a física e da astronomia da astrologia e da numerologia, segundo da Costa, radica essencialmente na atitude de quem cultiva essas disciplinas, de sua postura metodológica. Assim, segundo da Costa, um astrólogo que utiliza instrumentos de precisão, mapas astronômicos, alguma matemática e alguma física, pode proceder cientificamente, ainda que seus resultados (por exemplo, um horóscopo) sejam destituídos do caráter de cientificidade que se espera haja com as previsões científicas propriamente ditas, como repetições por grupos de cientistas independentes e carência de ambigüidade. A ciência "prática", portanto, para ele, em grande parte é identificada com a metodologia. Assim, se a atitude do pesquisador for metodologicamente racional e científica, podemos, segundo ele, dizer que o que o investigador realiza é ciência, mesmo que não seja fecunda e que deva ser drasticamente restringida, praticamente abandonada. A questão da vinculação da atividade científica ao método, no entanto, deve ser vista com cautela. Muitas vezes, insights aparentemente vindos do nada, a não ser do conhecimento prévio e profundo do cientista, introduzidos nas disciplinas científicas sem que possam ser enquadrados em qualquer técnica metodológica, podem se mostrar extremamente férteis e originais. Um bom exemplo foi a hipótese de Planck dos quanta de luz, lançada por ele de forma genial em um "ato de desespero", mas que originou uma das maiores conquistas científicas de todos os tempos, a física quântica.

No entanto, a posição de da Costa de que há um interplay entre ciência e metodologia me parece certa. Como ele poderia dizer, um dos grandes paradoxos relacionados à distinção entre ciência e não ciência é o seguinte. No decorrer da história, como vimos, muitas disciplinas que eram tidas como científicas deixaram se sê-lo. Por outro lado, especulações que eram tidas como não científicas adquiriram o status de ciência. Um exemplo é a proposta de Augusto Comte de que a astronomia deveria se restringir ao simples estudo geométrico e mecânico dos astros, pois uma ciência, e.g., da constituição do Sol era para ele inconcebível. Não obstante, pouco tempo depois, Bunsen constatou a existência de helio no Sol. Este paradoxo, segundo da Costa, confirma plenamente que a ciência depende da metodologia, tanto como essa

Principia 13(2): 105-28 (2009). 
depende daquela, fato este que não se pode, ao que tudo indica, negar.

Em resumo, a ciência, para da Costa, é um fazer pragmático, estando determinado por fatores pragmáticos os mais variados, podendo-se incluir, em sentido amplo, até mesmo aqueles de origem estética, de moda ou de autoridade.

\section{A dimensão histórica da ciência}

Resta um último ponto para ser abordado neste breve passeio sobre concepções que permeiam a filosofia da ciência de Newton da Costa. Para ele, como já salientamos anteriormente, é ponto pacífico que a filosofia da ciência tem um caráter histórico, retratando a ciência apenas relativamente a um determinado momento. Com efeito, nada impede que, no futuro, o que hoje é considerado como 'científico' vá ser classificado de outra forma, como já observamos com respeito à astrologia. Com efeito, a ciência se desenvolve e se estrutura no decurso da história, não se podendo, por assim dizer, prever o seu estado futuro. Uma das primeiras teorias da ciência foi a de Aristóteles, na qual os axiomas e definições expressavam (assim se supunha) fatos reais, e toda a ciência se desenvolvia silogisticamente. A teoria aristotélica, genial para a sua época, não reflete mais o estado atual da ciência e da atividade científica. Aliás, pode-se dizer que ela já não refletia a ciência originada com Galileu e ampliada por Newton, a qual constitui a base da ciência atual. A ciência de Galileu e Newton, por sua vez, devido a descobertas revolucionárias originadas pela física quântica e pela relatividade, também já não se enquadra mais no âmbito da ciência atual. Cóm efeito, tal concepção era determinista, ou seja, a situação do universo em um determinado instante determinava sua situação em qualquer outro instante de tempo. Aliás, as próprias noções de espaço e de tempo cambiaram radicalmente com o advento da relatividade geral (ainda que não na física quântica usual, fato este que constitui um dos pilares para sua incompatibilidade).

É óbvio que a metodologia da ciência depende da própria ciência mas, por outro lado, influencia a ciência. Por exemplo, as idéias de Claude Bernard influenciaram profundamente a medicina no estabelecimento de princípios experimentais; Bernard é um dos fundadores da medicina experimental. Por outro lado, a postura metodológica de Galileu como que determinou o espírito norteador da física a partir do século XVII. Tudo isso é refletido na posição de da Costa de encarar a metodologia e a teoria da ciência em geral como um corpo de doutrinas que evoluem no decurso do tempo, ora refletindo e descrevendo o que se passa no campo científico, ora prescrevendo o que deveria se passar. Sua concepção de ciência e da atividade científica, portanto, deve ser encarada como algo dependente do tempo, a qual pode-se reputar como válida hoje, mas que certamente terá que ser modificada no futuro. Assim, como se vê, trata-se de uma posição nada hirta, permitindo uma grande flexibilidade de

Principia 13(2): 105-28 (2009). 
concepções, que se adapta ao próprio progresso do fazer científico. Aliás, essa é uma das características de da Costa como cientista e filósofo: não ter e não conceber que se tenha opiniões imutáveis e definitivas.

\section{Da Costa, filósofo ou matemático?}

Devemos chamar de 'filósofo' somente aquele que obteve formalmente um grau em filosofia (por exemplo um diploma universitário)? Claro que isso seria um abuso. No decorrer dos 25 anos que convivo com Newton da Costa, já ouvi este argumento contra as suas investidas em filosofia. Assim, segundo algumas pessoas, da Costa seria um matemático ou, mais propriamente, um lógico matemático, já que trata seus assuntos com bastante técnica, dando preferência a discussões filosóficas nas quais os argumentos possam ser fundamentados com base na lógica e na matemática. Neste particular, ele parece seguir Carnap, quando este afirmou que poderia entender claramente um conceito ou uma proposição ocorrendo em uma discussão científica ou filosófica somente se pudesse expresso em uma linguagem simbólica. ${ }^{10}$ Por outro lado, para certa parte da comunidade matemática, um matemático é alguém que se ocupa especificamente da matemática e de suas aplicações, e que não divaga em questões filosóficas, como discutir acerca da verdade ou das bases lógicas da ciência. Também já ouvi esse argumento com o fito de atestar que da Costa não seria um matemático, mas um filósofo, principalmente porque os matemáticos brasileiros, via de regra, dão pouca ou nenhuma atenção à lógica, que para eles seria assunto da filosofia. Afinal, em que categoria devemos classificá-lo? Ora, por que devemos classificá-lo segundo padrões tão estreitos? Segundo o primeiro critério, Gödel, Tarski e Hermann Weyl não seriam filósofos, apesar de terem dado contribuições notáveis à filosofia. Pelo segundo, Descartes e Leibniz não seriam matemáticos, não obstante a sua excepcional obra nessa disciplina. Tudo isso é, com efeito, implausível. A obra de um cientista se mede e se classifica pelo alcance de suas idéias e pelas articulações que possibilita, ainda que, muitas vezes, isso possa acontecer somente muito a posteriori. (Há vários exemplos desse tipo na história da ciência; o caso de Hermann Günther Grassmann (1809-1877) é um exemplo. Seus trabalhos, como os do desenvolvimento da álgebra linear e da álgebra multilinear, notadamente a definição de espaço vetorial, um dos principais conceitos da matemática atual, somente foram reconhecidos após a incursão de Hermann Weyl, na década de 1920). Da Costa, por sorte, teve a felicidade de ver suas idéias difundidas por boa parte do globo, infelizmente sendo pouco (para os padrões da sua riqueza) explorados em nosso país.

Essas observações não visam, é claro, desmerecer quem se dedica a fundo a uma área restrita do conhecimento, mas tal restrição de escopo não é o modo de da Costa

Principia 13(2): 105-28 (2009). 
de fazer filosofia ou ciência. Apesar de ele ser dotado de uma enorme capacidade técnica em vários domínios, em especial em matemática, ele se dedica a idéias gerais, porém não deixando de fundamentar o que pretende sobre alicerces firmes. Um típico exemplo é a noção de quase-verdade, ou da consideração da possibilidade de se conviver com inconsistências. Em ambos os casos, ele não somente teceu considerações de natureza filosófica, mas fundamentou matematicamente suas idéias. Seu estilo de fazer filosofia é precisamente este, exigindo que as discussões não sejam meramente opinativas, mas fundamentadas em bases argumentativas sólidas, posição que ele diz se inspirar em Tarski. Aliás, costuma mencionar uma frase que diz ter aprendido em correspondência com Georg Kreisel, um dos maiores lógicos ainda vivos: em ciência, o filósofo deve cultivar TENOS, ou seja, "Technical Expertise, Not Only Speculation". Da Costa segue essa máxima à risca.

Aliás, as críticas mencionadas acima não se resume a da Costa, mas a todos os que trabalham como ele, fato que no entanto não se estende aos países de primeiro mundo, nos quais o conhecimento técnico é condição sine qua non para um trabalho razoável em filosofia da ciência. Claro que da Costa não desdenha a especulação em áreas nas quais ela é essencial e consiste, na verdade, na própria essência da filosofia, mas ele não se dedica a tais assuntos, acreditando unicamente que a filosofia da ciência empírica, da matemática e da lógica, não podem proceder por mera especulação. Infelizmente, é via de regra pouco compreendido neste particular. Porém, suas ações têm contribuído positivamente para a formação de uma escola de filosofia da ciência que leva em conta o devido preparo em aspectos técnicos, partindo do pressuposto de que, para se fazer filosofia de alguma disciplina, essa disciplina deve ser minimamente dominada em primeiro lugar. Esperamos que o seu exemplo possa influenciar o futuro da filosofia da ciência no Brasil de forma a podermos nos equiparar em futuro breve ao que se faz nos países mais avançados cientificamente, e que deixemos de fazer quase que exclusivamente história da filosofia da ciência, malgrado a sua importância.

\section{Referências}

Bourbaki, N. 1968. Theory of Sets. Boston and Reading, Mass.: Hermann and Addison Wesley. Chisholm, R. 1966. Theory of Knowledge. New Jersey: Prentice-Hall.

da Costa, N. C. A. 1980. Ensaio sobre os Fundamentos da Eógica. S. Paulo: EdUSP e Hucitec.

(2. ed. Hucitec 1994, 3. ed. 2008.) 1981. Lógica Indutiva e Probabilidade. S. Paulo: IME-USP. (2. ed. Hucitec 2008.) 1986. Pragmatic probability. Erkenntnis 25: 141-62.

1989. Logic and pragmatic truth. In J. E. Fenstad (ed.) Logic, Methodology, and Phi-

losophy of Science VIII. Amsterdam: Elsevier, 247-61.

- 1990. Memorial Científico. (não publicado)

Principia 13(2): 105-28 (2009). 
Lógica Indutiva e Probabilidade. São Paulo: Hucitec-EdUSP. (2a. ed. 1993, 3a. ed. 2008.)

1999. O Conhecimento Científico. 2. ed. São Paulo: Discurso Editorial.

da Costa, N. C. A. \& Dubikajtis, L. 1977. On Jaskowski's Discussive Logic. In A. I. Arruda, N. C. A. da Costa, and R. Chuaqui (eds.) Non-Classical Logics, Model Theory and Computability. Amsterdam: North-Holland Publishing Company, 37-56.

da Costa, N. C. A. \& Chuaqui, R. 1988. On Suppes' set-theoretical predicates. Erkenntnis 29: 95-112.

da Costa, N. C. A. \& French, S. 2003. Science and Partial Truth: A Unitary Approach to Models and Scientific Reasoning. (Oxford Studies in Philosophy of Science). Oxford: Oxford University Press.

da Costa, N. C. A. \& Krause, D. 1994. Schrödinger logics. Studia Logica 53(4): 533-50.

\section{9-94.}

- 2006. The logic of complementarity. In J. van Benthem, G. Heinzmann, M. Rebuschi and H. Visser (eds.) The Age of Alternative Logics: Assessing Philosophy of Logic and Mathematics Today. Dordrecht: Springer, 103-20.

da Costa, N. C. A. \& Bueno, O. 2007. Quasi-Truth, Paraconsistency, and the Foundations of Science. Synthese 154: 383-99.

da Costa, N. C. A.; Bueno, O.; French, S. 1998. Is there a Zande Logic? History and Philosophy of Logic 19: 41-54.

da Costa, N. C. A.; Krause, D.; Bueno, O. 2007. Paraconsistent logics and paraconsistency. In D. Jacquette (ed.) Philosophy of Logic. Amsterdam: Elsevier, 655-781. Vol.5 da série Handbook of the Philosophy of Science, D. M. Gabbay, P. Thagard and J. Woods (eds.)

Davies, R. B. 2005. Some remarks on the foundations of quantum theory. Brit. J. Phil. Sci. 56: 521-39.

Jennings, R. C. 1989. Zande logic and western logic. British J. Phil. Sci. 40(2): 275-85.

Krause, D. Lógica paraconsistente. 2004. Scientific American Brasil. Novembro 2004, 70-77.

Krause, D. \& Bueno, O. 2007. Scientific theories, models, and the semantic approach. Principia 11(2): 187-201.

Mikenberg, I.; da Costa, N. C. A.; Chuaqui, R. 1986. Pragmatic truth and approximation to truth. Journal of Symbolic Logic 51: 201-21.

Peiffer, J. 2002. France. In J. W. Dauben, and Scriba, C. J. (eds.) Writing the History of Mathematics: Its Historical Development. Berlin: Birhkauser Verlag, 3-43.

Popper, K. R. 2002. The Logic of Scientific Discovery. London: Routledge.

Evans-Pritchard, E. E. 2005. Bruxaria, Oráculos e Magia entre os Azande. Rio de Janeiro: Jorge Zahar.

Schilpp, P. A. (ed.) 1963. The Philosophy of Rudolf Carnap. Ea Salle, Il.: Open Court Publishing Co.

Suppes, P. 2002. Representation and invariance of scientific structures. Stanford: CSLI.

Suppes, P. \& Luce, R. D. 1987. Measurement theory. Encyclopedia Britannica, 15th ed., vol. 23.

von Wright, G. H. 1951. A Treatise on Induction and Probability. New York: Harcourt, Brace and Co.; London: Routledge \& Kegan-Paul.

Principia 13(2): 105-28 (2009). 


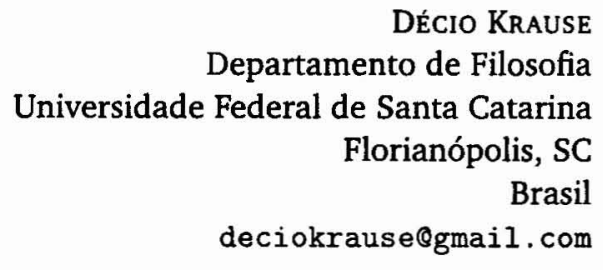

Resumo. Este artigo pretende introduzir os três volumes de Principia que aparecerão em sequência homenageando os 80 anos do professor Newton da Costa. Ao invés de apresentar os artigos um a um, como se faz usualmente em uma introdução como esta, preferimos deixar os artigos falarem por si, e fornecer aos leitores brasileiros, especialmente nossos estudantes, alguns aspectos da concepção de ciência e da atividade científica de Newton da Costa, fundamentadas no conceito de quase-verdade, que ele contribuiu para desenvolver de modo rigoroso. Da Costa é conhecido como um dos fundadores da lógica paraconsistente, mas suas contribuições alcançam também os fundamentos da física, da ciência da computação,a teoria dos modelos, a lógica algébrica, a teoria dos reticulados, as aplicações de lógicas não-clássicas à ciência do direito e à tecnologia, etc. No entanto, talvez sua maior contruição tenha sido proporcionar a base para a criação de uma escola de lógica em nosso país (Brasil), à qual serviu como professor e inspirador por gerações. É com satisfação que vimos uma imediata aceitação pelos editors de Principia para a organização desses volumes. Gostaria de agradecer a todos os que contribuíram com artigos e aos editors da revista, em especial ao professor Cezar Mortari pela ajuda na organização desta homenagem.

Palavras-chave: Newton da Costa, quase-verdade, atividade científica, ciência.

\section{Notas}

${ }^{1}$ Sem muito rigor, uma lógica é paraconsistente se pode fundamentar teorias inconsistentes, ou seja, que admitam teses contraditórias, sem que sejam triviais, ou seja, sem que todas as fórmulas de sua linguagem sejam teoremas da teoria. Na lógica clássica, bem como na maior parte dos sistemas conhecidos, como a lógica intuicionista, de duas proposições contraditórias pode-se derivar qualquer proposição: ex falso sequitur quodlibet. Uma exposição informal das idéias básicas de tais lógicas pode ser vista em (Krause 2004).

${ }^{2}$ Segundo antropólogos como Evans-Pritchard (2005), os Azande formulam certas formas de raciocínio que ferem as regras da lógica tradicional. Isso, no entanto, como é de se prever, é discutível (Jennings 1989).

${ }^{3}$ Há vários artigos detalhados sobre diversas concepções do conceito de verdade na Stanford Encyclopedia of Philosophy, http://plato. stanf ord. edu, que o leitor pode consultar, os quais contêm referências adicionais.

${ }^{4} \mathrm{Da}$ Costa e French evidenciaram ainda que a teoria da verdade como coerência pode ser identificada como uma versão sintática da teoria da quase-verdade, de modo que, em certo sentido, defender a teoria da coerência significa defender a quase-verdade. Assim, posições

Principia 13(2): 105-28 (2009). 
como as de Hahn, Bradley, Bosanquet e Rescher, por exemplo, quando devidamente matematizadas, constituem duais sintáticos da teoria da quase-verdade.

${ }^{5}$ Sem rigor, o teorema de de Finetti asserta que probabilidades conferidas a priori, inicialmente arbitrárias, vão com o tempo convergindo e tendendo à estabilidade, mudanças essas que são estabelecidas pela chamada Lei de Bayes.

${ }^{6}$ No entanto, perto das dimensões da chamada 'escala de Planck', cerca de $10^{-33} \mathrm{~cm}$, fenômenos relativistas aparecem de forma essencial, segundo as teorias físicas mais recentes, o que exige uma aplicação conjunta da relatividade geral e da física quântica, junção esta que até o momento não se sabe precisamente como sistematizar em uma teoria sensata.

${ }^{7}$ A matemática de Solovay é mais ampla que aquela que é erigida em ZFC. Por exemplo, nela, todo operador linear sobre um espaço de Hilbert é limitado, mas na mecânica quântica usual necessita-se de operadores não limitados. Assim, se usarmos Solovay para descrever as estruturas quânticas usuais, possivelmente nos depararemos com dificuldades.

${ }^{8}$ Falando por alto, suponha que temos duas teorias $T_{1}$ e $T_{2}$ incompativeis, porém com mesma lógica e linguagem básica (exceto talvez por alguns termos específicos), ou seja, tais que se possa dizer que existe uma sentença $S$ tal que $T_{1}$ prova $S$ e $T_{2}$ prova a negação de $S$. Se a lógica subjacente for a lógica clássica, então a teoria (formulada adequadamente) denotada esquematicamente $T=T_{1}+T_{2}$, será contraditória, pois em $T$ derivar-se-ia uma contradição. No entanto, se $T$ for fundada em uma lógica paraclássica, podemos ter então mesmo que $S$ e a negação de $S$ sejam teses de $T_{1}$ e de $T_{2}$ respectivamente, em $T$ sua conjunção não poderia ser derivada (da Costa \& Krause 2006).

${ }^{9}$ Como se sabe, havia dificuldade em se atribuir um 'significado' à função de onda $\psi$ que aparecia no formalismo quântico. Born propôs que o seu quadrado, $|\psi|^{2}$, representasse uma densidade de probabilidade.

${ }^{10}$ Mais precisamente, disse ele: "When I consider a concept or a proposition occurring in a scientific or philosophical discussion, I thought that I understood it clearly only if I felt that I could express it, if I wanted, in a symbolic language." (ver sua Intellectual Autobiography, em Schilpp 1963, 11).

Principia 13(2): 105-28 (2009). 